THE JOURNAL OF ECONOMIC HISTORY

VOLUME 76

DECEMBER 2016

NUMBER 4

\title{
The Lasting Impact of Grandfathers: Class, Occupational Status, and Earnings over Three Generations in Sweden 1815-2011
}

Martin Dribe and Jonas Helgertz

This article examines socioeconomic mobility across three generations in Sweden from 1815 and until 2011. Using longitudinal micro-level data from the Scanian Economic-Demographic Database (SEDD), we examine the transmission of socio-economic status along three different dimensions; social class (HISCLASS), occupational status (HISCAM), and earnings. We demonstrate an association between grandfathers' class or occupational status and the outcome of grandsons, when controlling for the association between fathers and sons. The associations remain stable over time and are stronger for paternal grandfathers than for maternal. For earnings, we find no grandparental association.

Oocioeconomic inequality in a historical perspective has recently received considerable attention. Thomas Piketty's Capital in the Twenty-First Century (2014) has increased public awareness of growing

The Journal of Economic History, Vol. 76, No. 4 (December 2016). (C) The Economic History Association. All rights reserved. doi: 10.1017/S0022050716000991

Martin Dribe is Professor of Economic History, Department of Economic History and Centre for Economic Demography, Lund University, P.O. Box 7083, 22007 Lund, Sweden. E-mail: Martin.Dribe@ekh.lu.se. Jonas Helgertz is Associate Professor of Economic History, Department of Economic History and Centre for Economic Demography, Lund University, P.O. Box 7083, 22007 Lund, Sweden. E-mail: Jonas.Helgertz@ekh.lu.se.

This work is part of the research program "The Rise and Fall of the Industrial City: The Landskrona Population Study," funded by the Bank of Sweden Tercentenary Foundation. Previous versions of the paper have been presented at the Social Science History Association (2013), Economic History Society (2014), Allied Social Sciences Associations (2015), and at conferences on social mobility at the University of Toulouse (2014) and the Sungkyunkwan University in Seoul, South Korea (2015), as well as at seminars at the Universities of Copenhagen, Northwestern, Duisburg-Essen, Lund, Michigan, and Binghamton. We are grateful to discussants and participants at these seminars, and especially Joseph Ferrie, Laura Salisbury, and Anders Björklund for helpful comments and suggestions. Finn Hedefalk's assistance is also gratefully acknowledged. 
social and economic inequality globally. Perhaps even more concerning is evidence that a higher level of inequality in a country is associated with less intergenerational mobility and thus greater persistence in socioeconomic status across generations (Corak 2013).

In both sociology and economics, research into the causes and consequences of socioeconomic attainment has long been a core topic. Whereas the sociological literature largely focuses on occupation and class, economists have mainly examined monetary measurements, such as earnings and wealth. More specifically, economists have sought to quantify the process of regression to the mean; the degree to which an earnings (dis) advantage persists across generations, through the estimation of intergenerational earnings elasticities. Consistently across time and space, empirical studies of developed countries show considerable persistence in various measures of socioeconomic status from father to son (Solon 1992; Zimmermann 1992; Björklund and Jäntti 2000, 2009; Black and Devereux 2011; Jäntti and Jenkins 2013). More recently, scholars have begun to examine status transmission across three generations, from grandparents to grandchildren because a simple two-generation perspective (e.g., father-son correlations in socioeconomic outcomes) is likely to underestimate the strength of socioeconomic persistence across generations (Warren and Hauser 1997; Lindahl et al. 2015; Braun and Stuhler 2015; see also Mare 2011; Björklund and Jäntti 2012).

The aim of this article is to study three-generational associations in different socioeconomic outcomes for Swedish men over a 200-year period (1815-2011). While similar in focus to the study by Mikael Lindahl et al. (2015) we have a broader focus. Rather than examining a single cohort, we use data on multiple cohorts for a greater number of family lines, stretching further back in time. We also separately examine the role played by social class, occupational attainment, and lifetime earnings, thus offering a more comprehensive account of the multigenerational transmission of socioeconomic status than in the previous literature. Class, occupational status, and earnings are measured in prime working ages in each generation: Class is measured using the HISCLASS scheme (Van Leeuwen and Maas 2011); Occupational status is measured using the continuous HISCAM scale (Lambert et al. 2013; Prandy 1999); and lifetime earnings are estimated using annual observations on labor income. In addition to assessing the grandparent impact along the male line (paternal grandfather-father-son), as is done in most previous research, we also look at the influence of the status of maternal grandfathers, as well as the simultaneous influence of both maternal and paternal grandfathers. We also inquire whether the grandfather-grandson association is contingent upon social interaction between grandfathers 
and their grandsons, and the extent to which patterns change over time. This is done using individual-level data from the Scanian EconomicDemographic Database (SEDD) with information on socioeconomic attainment for cohorts born from the late 1700s until $1980 .{ }^{1}$

Our findings show a clear association over three generations in terms of class and occupational attainment, even when controlling for father's class or occupational status. Both maternal and paternal grandfathers show an association, but it is stronger for paternal grandfathers. The association is very stable over time, and there is some indication that it is stronger when the lifespans of grandfathers and grandsons overlap. In contrast, there is no three-generation association for earnings.

\section{PATTERNS AND DETERMINANTS OF MULTIGENERATIONAL INEQUALITY}

Much of the economic research on the intergenerational determinants of socioeconomic attainment derives its theoretical foundation from the highly influential model developed by Gary Becker and Nigel Tomes (1986). Because socioeconomic attainment (e.g., earnings or occupational status) is partly the result of parental investments in the human capital of their offspring, this results in a positive correlation of socioeconomic status in a two-generational setting. This theoretical postulate has been repeatedly confirmed in empirical studies by positive correlations in earnings between two consecutive generations (typically between fathers and sons) (Solon 1992; Zimmermann 1992; Björklund and Jäntti 2000, 2009; Black and Devereux 2011; Jäntti and Jenkins 2013). Country differences in the strength of the correlation are, however, not trivial, indicating considerable heterogeneity in intergenerational earnings persistence across different contexts (e.g., Blanden 2013; Corak 2013). ${ }^{2}$ Sweden, for example, appears to have higher earnings mobility, and thus lower intergenerational persistence in earnings than either the United States or Great Britain (Björklund and Jäntti 1997, 2000; Solon 2002).

A process of regression to the mean should cause the influence of earlier generations to gradually diminish. In fact, according to Becker and Tomes (1986), most ancestral influences are eliminated already after three generations in developed countries, giving little room for grandparental influence on their grandchildren's outcomes. This is consistent with a first-order Markov (AR1) process, where the outcome in one generation

\footnotetext{
${ }^{1}$ Bengtsson et al. 2014. The data is available at www.ed.lu.se/databases/sedd. Under Swedish law, only the data before 1916 can be downloaded without restrictions.

${ }^{2}$ Blanden's preferred estimates range from 0.14 in Denmark to 0.52 for Brazil, with Sweden at 0.24 .
} 
is only determined by characteristics of the parental generation (e.g., Hodge 1966). Several studies on class attainment based on occupation provide empirical support for this view, with no, or only a very limited, impact of grandparents' status on the status attainment of their grandchildren, once the status of the parents is controlled for (Hodge 1966; Warren and Hauser 1997; Erola and Moisio 2007; Braun and Stuhler 2015).

In contrast, there are studies that provide evidence suggesting important associations between socioeconomic outcomes of grandfathers and grandsons, over and above the influence from the parental generation. In a study of earnings and education across three generations using data from a cohort of school children from 1938 in Malmö in southern Sweden, Lindahl and his colleagues (2015) find a significant association between the education of grandparents and grandchildren, controlling for the impact of parental education. Grandparental influence on earnings is, however, much smaller. A first-order Markov process cannot fully describe the social mobility process in Sweden in the twentieth century. ${ }^{3}$

Bitte Modin, Robert Erikson, and Denny Vågerö (2013) examine education and find that ninth-graders in contemporary Sweden are more likely to achieve top grades in Mathematics and Swedish if their grandparents had high grades in these subjects in third grade. They do not control for parental grades but include controls for parental educational level (as well as the educational level of all grandparents), and interpret their results as evidence of a direct influence from grandparents to grandchildren in terms of school performance. Martin Hällsten (2014) exploits cousin correlations in several outcomes, finding a grandparental influence above and beyond that of the parents in terms of grade point average (GPA), years of education, and attained occupational prestige. Allowing for heterogeneous effects across different socioeconomic origins, the findings suggest that the grandparental influence is greatest among individuals from wealthy origins. ${ }^{4}$

\footnotetext{
${ }^{3}$ For twentieth century Germany, Braun and Stuhler (2015) find similar three generation associations in years of education, but they mostly disappear when adding controls for the schooling of the mother.

${ }^{4}$ Based on multilevel variance partitioning (intraclass correlations), Jaeger (2012) finds strong effects of (unobserved) shared factors between cousins on different educational outcomes, using the Wisconsin Longitudinal Study (WLS), but no direct (observed) effects from grandparental socioeconomic status (SES) and education on grandchildren's completed years of schooling. However, in contrast to Hällsten's (2014) results for Sweden, the impact of grandparental education for grandchildren is driven by low-status family origins. Modin and Fritzell (2009) also show a negative association between cognitive ability among Swedish conscripts (born 1960-1985) and the earnings of their grandfathers. Looking at contemporary China, Zeng and Xie (2014) find a clear influence of grandparents' education on grandchildren's likelihood of dropping out of school, but that this effect is contingent upon co-residence.
} 
For occupational attainment and mobility, studies of different contexts show significant associations between the attainment of grandfathers and grandsons, while controlling for the attainment of the fathers (Long and Ferrie 2012; Chan and Boliver 2013; Hertel and Groh-Samberg 2014; Braun and Stuhler 2015).

\section{MECHANISMS OF MULTIGENERATIONAL PERSISTENCE}

There are several reasons for the existence of a direct link between grandparents' and grandchildren's socioeconomic outcomes (Solon 2014). From a two-generational setting, Zhen Zeng and Yu Xie (2014) identify three main pathways of intergenerational influence: biological, economic, and socio-emotional. To the extent that genetics has an impact on ability and socioeconomic status (Beenstock 2012; Black and Devereux 2011; Björklund, Jäntti, and Solon 2007; Björklund, Lindahl, and Plug 2006), this could explain some maternal grandfather influence, while the impact from paternal grandfathers should be lower because most of the effect is mediated by the inclusion of father characteristics. Thus, a stronger association in status, on average, between maternal grandfathers and grandsons than between paternal grandfathers and grandsons could be interpreted as support for this kind of biological pathway, especially when the two are not geographically proximate.

Grandfathers can transmit economic resources directly to their grandsons in the form of human capital, wealth, or networks, which in turn could provide access to higher quality education or occupations (Mare 2011; Pfeffer and Hällsten 2012). Such direct influence through wealth and high-status networks should be most strongly felt at the upper end of the status distribution, and thus could be an explanation for a high degree of socioeconomic persistence among the upper classes (Zimmerman 1992). As with biological pathways, economic transfers do not require a close interaction between the generations through co-residence or geographic proximity. Networks and reputation could even remain important in cases when the grandfather is dead.

Socio-emotional factors or the transmission of cultural capital, on the other hand, require interaction between grandfathers and grandsons, which for most of the period covered in this study also presupposes residential proximity and that the grandfather is alive during the childhood of the grandson (Solon 2014; Zeng and Xie 2014). Decreased morbidity and increased longevity enhances the opportunity for grandparent impact (Bengtson 2001). At the same time, less intergenerational co-residence and the increasing importance of long-range migration work against this influence. 
Random measurement errors in socioeconomic status variables can create a spurious association between grandfathers and grandsons in multigenerational regressions of the kind used here (Solon 2014). Overall, we would expect such random measurement errors to be larger for income than for social class. However, because we will use estimates of life-time income based on multiple observations of both earnings and occupation, the impact of the measurement errors should be significantly reduced (cf. Solon 1992). Variations in "market luck" could also create a similarly spurious grandparent effect (Stuhler 2012). This relates to the hypothesis that some latent factor determines socioeconomic outcomes, such as earnings, occupation or education, and this factor is reproduced between generations at a much higher rate than the outcomes we can measure (Clark 2014; Clark and Cummins 2015). This could also explain why an association in observed outcomes between grandfathers and grandsons, net of the association between fathers and sons, can be found even in cases of a two-generational (Markov) transmission of the latent factor (Braun and Stuhler 2015). This means that we cannot interpret a "grandparent effect" as proof of a direct impact from grandfathers to grandsons without further qualifications.

\section{THE CONTEXT}

This analysis is about long-term patterns of social mobility in Sweden, covering the period from the early nineteenth century to the early twentyfirst century. As all other Western countries, Sweden underwent a radical transformation over these two centuries as a result of the agricultural and industrial revolutions, which together with the demographic transition, urbanization, the introduction of parliamentary democracy, and the development of a comprehensive welfare state, fundamentally changed the living conditions of its inhabitants. From being a poor agriculturallybased undemocratic monarchy in the early nineteenth century, Sweden transformed to one of the richest industrial democracies in the post-WWII period (Schön 2000). In the first half of the nineteenth century, Swedish agriculture was in the midst of the agricultural revolution in which institutional and technical change contributed to increased productivity, both per acre and per employed (Schön 2000; Svensson 2006; Olsson and Svensson 2010). Intimately connected to this development and the rising income of farmers, early industrialization began in textile production (Schön 1979). Later in the nineteenth century industrial production increased rapidly also in other sectors such as lumber, mining, and engineering leading to an industrial breakthrough (Schön 2000). 
This development continued in the twentieth century, which also saw the establishment of a multi-party parliamentary system. From the 1930s to the mid-1970s this party system was dominated by the Social Democratic (Labor) party, and the period especially after WWII saw rapid social reforms and the development of an extensive welfare state. One field of reform concerned education, resulting in a considerable increase in school participation in the post-war period. The percentage of all 16-year-olds completing at least nine years of schooling increased from about 4 percent in 1930 to about 26 percent in 1965 (Stanfors 2007, p. 188). This was the first stage of a change which suggests that people were increasingly eager to take up white-collar jobs, as those destined for blue-collar jobs typically left school after the mandatory six to seven years (Folkskola). The increasing importance of school participation potentially allowed the use of more meritocratic procedures in recruitment and promotion in the white-collar sectors (Dribe, Helgertz, and van de Putte 2015). Since the 1960s higher education has continuously grown in importance.

Our analysis is based on data from a community of five parishes in Scania in southern Sweden (see Figure 1). The economic and social development in the area under study reflects the overall trends for the country as a whole (Dribe, Helgertz, and van de Putte 2015). During the examined period, a part of the area (Kävlinge) changed from being a typical rural area, primarily engaged in grain production and animal husbandry, into a small industrial town characterized by food and textile industries as well as being a local center for business and administration. Another part of the area remained rural, but was transformed as agriculture became more and more mechanized and farm sizes increased substantially, leading to a rapid depopulation of the countryside in the second half of the twentieth century.

\section{DATA AND METHOD}

We use data from the Scanian Economic-Demographic Database (SEDD). These data, collected by researchers at the Centre for Economic Demography, Lund University and available at www.ed.lu.se/databases/ sedd, consists of individual-level longitudinal information on socioeconomic attainment and origin for individuals in the five parishes (Bengtsson et al. 2014). The database is one of very few that can follow individuals across multiple generations from preindustrial times up until the present, and with detailed information on occupation and income at the individual level. The parishes are of course not a representative 


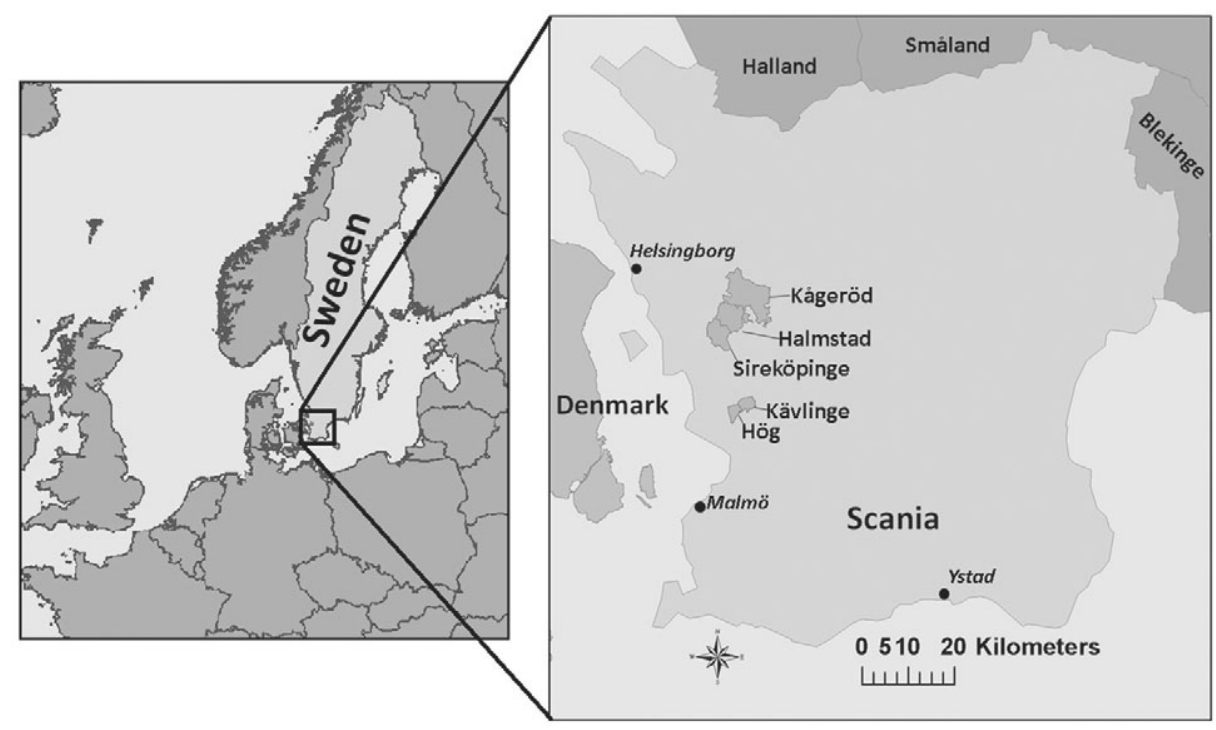

FIGURE 1

STUDY AREA

Source: Map created by Finn Hedefalk, Lund University. Used with permission.

sample of Sweden in a statistical sense, but the area is not atypical and reflects conditions shared by most rural and semi-urban areas of the time studied (see Dribe, Helgertz, and van de Putte 2015). In this analysis we study attainment during the period 1815-2011, including individuals born between 1777 and 1980. Until 1967, the data covers all individuals living in the five parishes. Information is provided from continuous population registers (a household-based register where information at the individual level is continuously updated), with information on demographic events, including migration to and from households for all individuals in the selected parishes. Birth and death registers have been used to adjust for possible under-recording of events in the population registers. Information on socioeconomic attainment is obtained from the population registers, vital event registers, poll-tax registers (mantalslängder), and from annual income and taxation registers which are available from 1902.

From 1968, individual-level information covering the entire country is available from various administrative registers, maintained by Statistics Sweden. This allowed us to extend the database along several dimensions. First, individuals who ever lived in the five parishes prior to 1968 and who were still alive in that year were followed until 2011, or until death or emigration, regardless of their geographic location in Sweden. 
Additionally, spouses, parents, grandparents, children and siblings of individuals belonging to the original population in Scania were added to the database, provided that they were alive and living in Sweden sometime after 1967. All individuals added to the sample population were similarly followed until 2011, death, or emigration from Sweden.

In the period before 1968, migration could potentially introduce selection bias, as it was both frequent and selective (Dribe 2003a, 2003b; cf. Abramitzky, Boustan, and Eriksson 2012). To deal with this all individuals in the sample have been traced back to their place of birth to get information on the occupation of their fathers. ${ }^{5}$ As a result, we obtained information on father's occupation for in-migrants allowing us to include them in the analysis as well. There is of course a potential problem also with selective out-migration in the period prior to 1968. Migrants leaving the area before being recorded with occupation or income are lost to follow-up. However, migration tended to be circular as shown by the fact that in-migrants and out-migrants from the area were similar in terms of origins and destinations. About 30 percent moved to any of the four major cities in the area (Landskrona, Helsingborg, Lund, and Malmö), and about the same proportion originated in these cities (calculations from the same dataset as is used in the empirical analysis). About 45 percent of out-migrants moved to places in the immediate vicinity (same municipalities), while the corresponding figure for the origins of the in-migrants were 37 percent. In- and out-migrants also had fairly similar socioeconomic status. Mean occupational status measured on the HISCAM scale (discussed later) differed only by 0.6 index points between in-migrants and out-migrants (index ranges from 1 to 99). Similarly, the proportions in different classes (HISCLASS) were highly similar, differing by only 1-2 percentage points. Out-migrants had somewhat higher proportions in higher occupations (10 percent versus 8 percent for in-migrants) and somewhat lower proportions in the working class (26 percent versus 28 percent for in-migrants in the group unskilled workers).

These similarities in observed characteristics between in- and outmigrants lead us to believe that these groups were fairly similar in terms of unobserved factors related to status (e.g., ability), which implies that the two migrant groups should roughly balance each other out. What is important is that we have both migrants and stayers in the sample, which

\footnotetext{
${ }^{5}$ Place of birth is given in the population registers and this information was used to identify the individuals in the birth registers and the population registers of the home parish at the time of birth. Of all the men who moved into the area and were observed with an occupation $(\mathrm{N}=14,345)$, we obtained information on their fathers' occupations in 83 percent of the cases.
} 
significantly reduces the risk of bias in the analysis stemming from selective migration. Nonetheless it is impossible to completely rule out the possibility that there are some systematic differences between in-migrants and out-migrants that we were unable to capture.

Figure 2 summarizes the linkage of the data across the generations and the attrition at different steps of the process. There are 132,400 males observed in the database in the period 1815-2011. We have 38,700 links from son to father and approximately 15,600 individuals linked three generations back in time. Because data are not available uniformly for all outcomes, the potential sample sizes for analyzing three generation occupational status and earnings are 8,500 and 5,500 individuals, respectively. More specifically, the earliest information on the attained occupational status for a (linked) grandfather is for those born in 1777, and the latest for those born in 1960. Earnings data only allows for the observation of linked grandfathers for cohorts born between 1892 and 1980. As a result of missing information on the outcome variable in any of the three generations, the realized samples used in the analysis are 4,300 (51 percent of the potential sample) for occupation and 2,200 (40 percent) for earnings. ${ }^{6}$ The analysis of earnings spans the period 1902-2011, whereas the analysis of occupation covers the period 1813-1990. We conduct a sensitivity analysis using an identical, but smaller sample to ascertain that the different samples do not drive the results we base the conclusions of this article on.

Individuals often have multiple observations on occupation (average about 3 ) and earnings (average about 13) in the registers. Having these multiple observations is especially important for the study of income mobility because single measures of income tend to exaggerate measurements of mobility (Solon 1992).

Prior to 1968, the analyses of class and occupational status use data obtained from several sources: demographic events, population registers, as well as annual data from the poll-tax registers and income registers. After 1968, we rely on occupational information provided by the quinquennial censuses (1970-1990). For the period before 1968, occupational notations in SEDD are coded according to an internationally comparable

\footnotetext{
${ }^{6}$ This sample is substantially larger than the one used in Lindahl et al. (2015) which included about 900 family lines. Compared to that study we also have more data on income going farther back in time, and also more frequently recorded in the pre-1985 period. Our data on occupation enables us to provide a detailed analysis not only of income persistence across generation but also of class and occupational status attainment. We also make a systematic distinction between the influence of paternal and maternal grandparents and examine whether the grandparental association is contingent upon grandparents being alive at the time of birth of the grandson.
} 


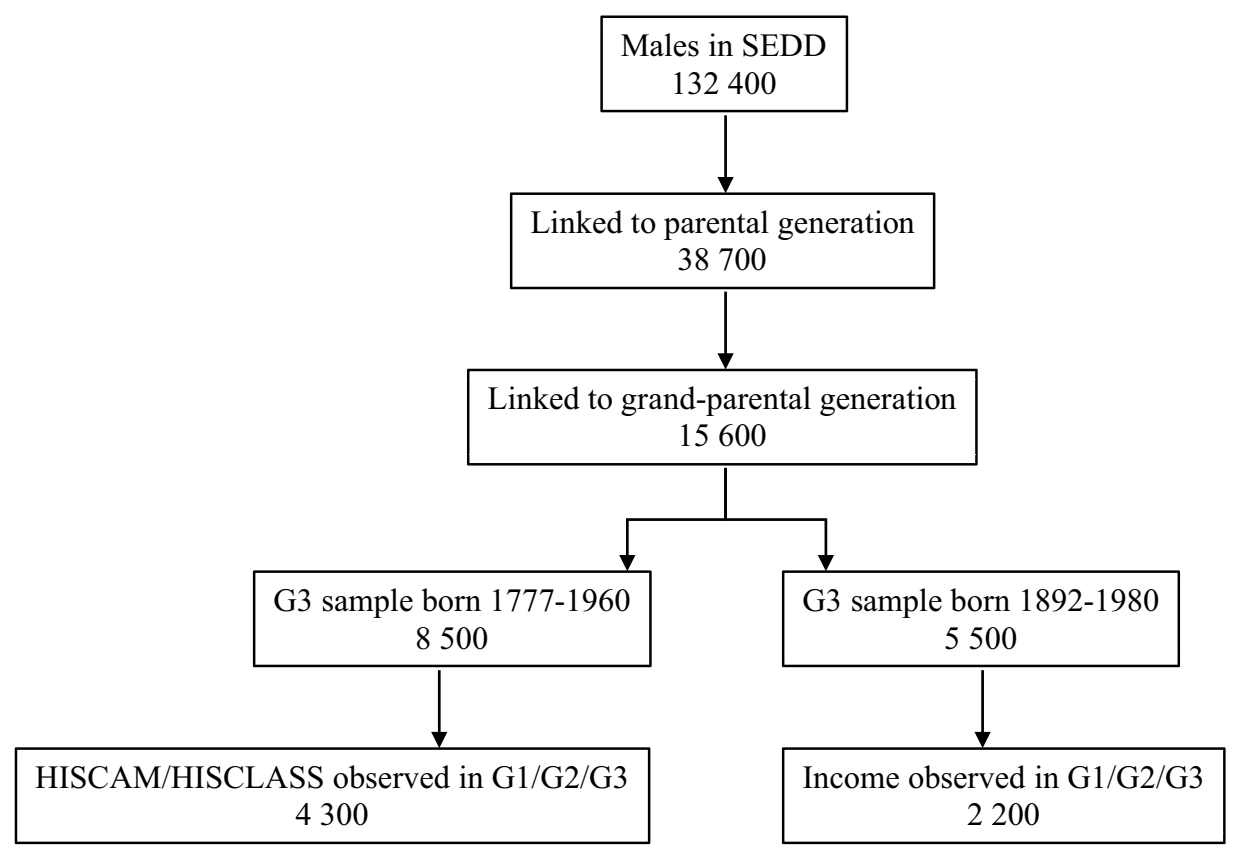

FIGURE 2

OVERVIEW OF THE SAMPLE CONSTRUCTION

(OBSERVATIONS ROUNDED UP/DOWN TO NEAREST ONE HUNDRED)

Source: See Table 1.

coding scheme for historical occupations (HISCO) (Van Leeuwen, Maas, and Miles 2002). Occupations observed after 1968 were originally coded by Statistics Sweden in the NYK/SSYK classification, and were recoded into $\mathrm{HISCO}^{7}$ after first being converted from ISCO- $88^{8}$ into ISCO-68 (Hendrickx 2002). Hence, all occupations are coded in HISCO. While an individual may have several occupational notations at different times and from different sources, we use observations for prime working ages between 30 and 50 . When available, the occupation of the father is measured in the same way or at time of the birth of his son, which generally occurs within the age range 30-50.

In the analysis, we exploit socioeconomic information on both the maternal and paternal grandfather. Because information for both grandfathers is sometimes missing, we also conduct an analysis based on the highest attainment in the grandparental generation, regardless of whether it refers to the paternal or maternal side.

\footnotetext{
${ }^{7}$ We have reversed the HISCO to ISCO-68 code, created by Ineke Maas, Utrecht University.

${ }^{8}$ We have used the recoding files created by Erik Bihagen, Stockholm University.
} 
We look at three different dimensions of socioeconomic status: social class, occupational status, and earnings. The summary statistics for individuals by social class (HISCLASS), occupation (HISCAM), and earnings are given in Table 1. Social class is measured at about the same age for all generations (the observation closest to age 40) according to HISCLASS, which is a 12-category occupational classification scheme based on skill level, degree of supervision, whether manual or non-manual, and whether urban or rural. ${ }^{9}$ We group the 12 classes into five which are described in Table 1. About 12 percent of grandfathers belonged to the top group of higher occupations, while this proportion increased to 30 percent for grandsons. At the same time, the proportion of farmers went down from 36 percent to 14 percent reflecting the changes taking place in social structure over the twentieth century in Sweden (Dribe, Helgertz, and van de Putte 2015).

Occupational status is measured by the continuous HISCAM scale, which determines the position of an occupation in the overall hierarchy based on social interaction patterns, mainly using information on marriage and partner selection (Lambert et al. 2014). It relies on patterns of interaction between incumbents of different occupations, translating into a relative position in a social hierarchy. HISCAM is generated from the HISCO codes, standardized to have a mean of 50 and a standard deviation of 15 in a nationally representative population, ranging from 1 to 99 (19-99 in our sample). ${ }^{10}$ We use the universal scale rather than the Sweden-specific version, due to the small sample size used in constructing the Swedish HISCAM scale.

Earnings are measured as the annual income from paid employment, including self-employment but excluding capital gains. We first estimate permanent lifetime earnings, to reduce the impact of measurement errors that could otherwise create artificial earnings mobility (Solon 1992; Zimmerman 1992; Björklund and Jäntti 1997). The same procedure is used for the continuous measure of occupational status (HISCAM). Following Lindahl et al. (2015), life-time earnings or occupational

\footnotetext{
${ }^{9}$ HISCLASS contains the following classes: (1) Higher managers; (2) Higher professionals; (3) Lower managers; (4) Lower professionals and clerical and sales personnel; (5) Lower clerical and sales personnel; (6) Foremen; (7) Medium skilled workers; (8) Farmers and fishermen; (9) Lower skilled workers; (10) Lower skilled farm workers; (11) Unskilled workers; and (12) Unskilled farm workers. These 12 classes were grouped in the following five categories; 1: Higher occupations (HISCLASS 1-5), 2: Skilled workers (6-7), 3: Farmers (8), 4: Lower skilled workers (9-10), and 5: Unskilled workers (11-12) (Van Leeuwen and Maas 2011).

${ }^{10}$ To give some examples, farmers have a score of 51 , laborers 47 , a postal clerk 78 , and university professors 99 .
} 


\section{Class, Status, Earnings-Three Generations in Sweden 981}

TABLE 1

DESCRIPTIVE STATISTICS

\begin{tabular}{|c|c|c|c|}
\hline & HISCLASS & HISCAM & EARNINGS \\
\hline Age at observation (mean) & 38.1 & 37.1 & 36.0 \\
\hline \multicolumn{4}{|l|}{ Place of residence (percent) } \\
\hline Metropolitan area & 40.2 & 39.0 & 52.4 \\
\hline County of birth & 87.4 & 85.2 & 85.6 \\
\hline Other county & 9.7 & 9.4 & 13.9 \\
\hline Migrant status N/A & 2.4 & 5.4 & 0.5 \\
\hline $\begin{array}{l}\text { Grandfather life status (perc } \\
\text { Alive at the time of birth of } \\
\text { individual }\end{array}$ & 25.0 & 22.5 & 76.8 \\
\hline $\begin{array}{l}\text { Dead at the time of birth of } \\
\text { individual }\end{array}$ & 12.3 & 12.6 & 8.9 \\
\hline N/A & 62.7 & 64.9 & 14.3 \\
\hline \multicolumn{4}{|l|}{ Period (percent) } \\
\hline 1813-1899 & 15.8 & 16.6 & - \\
\hline $1900-1944$ & 18.4 & 21.2 & - \\
\hline $1945-1990$ & 65.8 & 62.1 & - \\
\hline \multicolumn{4}{|l|}{ Birth year (mean) } \\
\hline \multirow[t]{2}{*}{ G3 } & 1914 & 1912 & 1962 \\
\hline & [1777-1960] & [1777-1960] & [1892-1980] \\
\hline \multirow[t]{2}{*}{ G2 } & 1882 & 1879 & 1933 \\
\hline & [1744-1942] & [1744-1941] & [1872-1961] \\
\hline \multirow[t]{2}{*}{ G1 } & 1844 & 1840 & 1906 \\
\hline & [1714-1920] & [1711-1919] & [1852-1945] \\
\hline
\end{tabular}

HISCLASS: G3 (Percent)

Higher occupations $\quad 30.0$

Skilled workers $\quad 17.6$

Farmers $\quad 13.6$

Lower skilled workers $\quad 27.2$

Unskilled workers $\quad 11.7$

HISCLASS: G2 (Percent)

Higher occupations 20.7

Skilled workers $\quad 16.6$

Farmers $\quad 25.2$

Lower skilled workers $\quad 26.6$

Unskilled workers $\quad 10.9$ 
TABLE 1 (CONTINUED)

DESCRIPTIVE STATISTICS

\begin{tabular}{lcc}
\hline \hline & HISCLASS & HISCAM \\
\hline HISCLASS: G1 (Percent) & & \\
Higher occupations & 12.1 & \\
Skilled workers & 16.2 & \\
Farmers & 35.7 & \\
Lower skilled workers & 23.0 & \\
Unskilled workers & 13.1 & \\
& & -0.007 \\
Average residual log HISCAM & & {$[-0.41-0.66]$} \\
G3 & & 0.019 \\
& & {$[-0.33-0.67]$} \\
G2 & & 0.017 \\
& & {$[-0.30-0.68]$}
\end{tabular}

Average residual log income

G3

0.002

[-5.49-1.44]

G2

[-5.02-2.52]

G1

Observations

4,261

4,282

2,241

Mean number of observations on outcome variable, G3

$3.2 \quad 3.3$

12.6

Note: Variable min and max values in brackets. Period effects not estimated for the income sample, as all G3 observations occur after 1943. The variable grandfather life status refers to the G1 grandfather with the highest observed SES, used in Table 7.

Source: The Scanian Economic-Demographic Database, Bengtsson et al. (2014).

status is obtained by regressing the individual's observed earnings or occupational status in year $t$ on year of birth, its square and cubic, as well as on a set of observation year dummies, following equation (1) and (2):

$$
\begin{gathered}
\log \left(\text { income }_{i t}=\alpha+\beta_{1} \text { birth year }_{i t}\right. \\
+\beta_{2} \text { birth year }_{i t}^{2}+\beta_{3} \text { birth year }_{i t}^{3}+\sum_{t} \gamma_{t} \text { year }_{i t}+\varepsilon_{i t}
\end{gathered}
$$




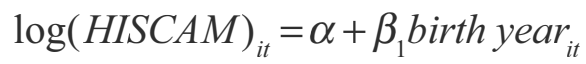

$$
\begin{aligned}
& +\beta_{2} \text { birth year }{ }_{i t}^{2}+\beta_{3} \text { birth year }{ }_{i t}^{3}+\sum_{t} \gamma_{t} \text { year }_{i t}+\varepsilon_{i t}
\end{aligned}
$$

In the subsequent step, each individual and year-specific residual, $\hat{\varepsilon}_{i t}$, is computed, and the mean of this residual is included in the threegeneration regressions, as a measure of lifetime earnings or HISCAM attainment. A value above zero indicates that the individual's performance is better than predicted by the individual's year of birth and period under observation. Essentially by construction, the lifetime measurements of HISCAM and earnings vary around zero for all three generations, as displayed in Table 1 ( -0.007 to 0.017 for average residual log HISCAM and -0.060 to 0.002 for average residual log earnings).

\section{EMPIRICAL RESULTS}

Our empirical analysis initially focuses on describing overall patterns of attainment across three generations, using mobility tables of social class (HISCLASS). The mobility tables show absolute mobility, and mainly serve to illustrate general patterns of multigenerational mobility. Table 2 presents origin and destination social class for fathers-sons (G2-G3), grandfathers-fathers (G1-G2), and grandfathers-grandsons (G1-G3). The grandfather observations are based on the sample which maximizes the number of observations, and takes the highest status observed in the grandparental generation, regardless of this being observed on the paternal or maternal side.

The figures on the diagonal represent the share of individuals remaining in the same class as their ancestors. More specifically, the panel displaying fathers and sons (G2-G3), indicate that 59.5 percent of the sons of fathers in higher occupations remain in this class. The figures off the diagonal display outflow percentages from each class, i.e., in which class people end up if they do not maintain the status of their ancestor, as indicated by the diagonal. Looking first at the top panel, displaying fathers and sons (G2-G3), there is a considerable inflow to the higher occupations from all classes, meaning that the sons achieved a higher class than their fathers. This is especially the case for upward mobility from individuals with skilled worker fathers, with 35.6 percent advancing into higher occupations. The same pattern is present, albeit to a slightly lesser extent, between grandfathers (G1) and fathers (G2), and of course also between grandfathers (G1) and grandsons (G3). Thus, even though there is a strong persistence in the highest-status group, as shown by the $50-60$ 
TABLE 2

MOBILITY TABLES, HISCLASS (PERCENT)

\begin{tabular}{lccccc}
\hline \hline & \multicolumn{5}{c}{ HISCLASS-5, G3 } \\
\cline { 2 - 6 } HISCLASS-5, G2 & $\begin{array}{c}\text { Higher } \\
\text { Occupations }\end{array}$ & $\begin{array}{c}\text { Skilled } \\
\text { Workers }\end{array}$ & Farmers & $\begin{array}{c}\text { Lower Skilled } \\
\text { Workers }\end{array}$ & $\begin{array}{c}\text { Unskilled } \\
\text { Workers }\end{array}$ \\
\hline Higher occupations & 59.5 & 15.0 & 4.4 & 17.3 & 3.9 \\
Skilled workers & 35.6 & 28.1 & 4.8 & 25.7 & 5.8 \\
Farmers & 15.5 & 11.3 & 35.0 & 24.1 & 14.2 \\
Lower skilled workers & 22.4 & 20.5 & 8.0 & 35.5 & 13.6 \\
Unskilled workers & 17.2 & 14.4 & 8.4 & 34.6 & 25.4 \\
\hline & & & HISCLASS-5, G2 & \\
\cline { 2 - 7 } & Higher & Skilled & \multicolumn{5}{c}{ Lower Skilled } & Unskilled \\
HISCLASS-5, G1 & Occupations & Workers & Farmers & Workers & Workers \\
\hline Higher occupations & 50.5 & 14.1 & 14.7 & 17.4 & 3.3 \\
Skilled workers & 28.3 & 30.7 & 12.5 & 22.7 & 5.8 \\
Farmers & 11.8 & 11.8 & 44.7 & 21.6 & 10.0 \\
Lower skilled workers & 17.2 & 15.1 & 17.4 & 35.5 & 14.8 \\
Unskilled workers & 14.0 & 17.3 & 11.0 & 37.8 & 20.0 \\
\hline & & \multicolumn{5}{c}{ HISCLASS-5, G3 } & \\
\cline { 2 - 7 } & Higher & Skilled & \multicolumn{5}{c}{ Lower Skilled } & Unskilled \\
HisCLASS-5, G1 & Occupations & Workers & Farmers & Workers & Workers \\
\hline Higher occupations & 49.3 & 15.1 & 10.4 & 19.7 & 5.4 \\
Skilled workers & 39.7 & 20.5 & 6.1 & 26.8 & 7.0 \\
Farmers & 23.3 & 15.0 & 24.2 & 24.5 & 13.0 \\
Unskilled workers & 24.4 & 18.6 & 9.3 & 30.4 & 17.4 \\
\hline SOurce: See Tkilled workers & 27.9 & 21.9 & 4.1 & 26.2 & 9.9 \\
\hline
\end{tabular}

Source: See Table 1.

percent immobile in this class, structural labor market changes implied a great increase in positions in higher occupations to allow individuals from lower class origins to move upwards in large numbers. In this way, class persistence and absolute class mobility occur at the same time. Moreover, downward class mobility is much less frequent than upward mobility, both between grandfathers and fathers (G1-G2) and fathers and sons (G2-G3). Overall, many people experience an important transition from manual, blue-collar jobs to non-manual, white-collar jobs, which often requires higher education.

Martin Dribe, Jonas Helgertz, and Bart van de Putte (2015) look in more detail at temporal changes in two-generational mobility and link 
them to the industrialization process. As is also documented in Table 2, they find that mobility into middle-class, white-collar occupations, was a result both of changes in the occupational structure affecting absolute mobility rates, and increased societal openness increasing mobility net of these structural labor market changes, referred to as relative mobility. Thus, while changes in the class structure by definition affect mobility chances through the amount of available positions in the labor market, changing relative mobility refers to alterations in mobility chances due to recruitment methods, etc. While overall mobility rates began to change early in the industrialization process largely due to more downward mobility (out of farming), increased upward mobility was more connected to the increasing role of achievement over ascription in occupational recruitment (e.g., Blau and Duncan 1967; Treiman 1970). The latter development did not become really important until the later stages of industrialization with increasing demand for formal education (Dribe, Helgertz, and van de Putte 2015).

\section{Class Attainment}

Next we examine the association between the grandfathers' social class and the class attainment of the grandsons, controlling for the fathers' class as well as a range of individual-level characteristics. Each regression model accounts for the fact that outcome variables for grandfathers aged 30-50 are observed with different frequencies. ${ }^{11}$

Due to the categorical, yet hierarchical, nature of the social class variable (HISCLASS), the grandparental influence is examined using an ordered logit model and the results are reported as unadjusted coefficients, or log odds ratios (see Table 3). The purpose of the analysis is not to assess the magnitude of the influence of prior generations, but simply to look at the associations, focusing on the log odds ratios for the parental and, in particular, grandparental influence. The models control for age of grandfather at the time of attainment, lifetime migration status,

\footnotetext{
${ }^{11}$ Whereas some individuals have observations every year in this interval, others are only observed for a few years. As was pointed out by Solon, Heider, and Wooldridge (2013), the analysis of group averages based on differing amounts of underlying observations using unweighted regression models is, under certain circumstances, likely to result in heteroscedasticity, with inefficiently estimated coefficients and inconsistent standard errors. Indeed, model tests suggested that this was the case. To account for this, weighted regression models with heteroscedasticityrobust standard errors were estimated, using analytical weights, equal to the number of unique observations on the outcome variable for each grandfather (see Baum 2006). Each individual is represented by a single observation and the analytical weights are based on the number of underlying observations used in estimating the outcome variable. While the models with weights are our preferred specification, results are similar in terms of sign and statistical significance when estimated without such weights (available from the authors on request).
} 
TABLE 3

ORDERED LOGIT ESTIMATES (LOG ODDS RATIOS) OF G3 CLASS ATTAINMENT (HISCLASS)

\begin{tabular}{|c|c|c|c|c|c|c|}
\hline & Model 1 & Model 2 & Model 3 & Model 4 & Model 5 & Model 6 \\
\hline \multicolumn{7}{|l|}{ G2 } \\
\hline Higher occupations & $\begin{array}{c}-1.268^{* * *} \\
(0.113)\end{array}$ & $\begin{array}{c}-1.211^{* * * *} \\
(0.133)\end{array}$ & $\begin{array}{c}-1.185^{* * *} \\
(0.130)\end{array}$ & $\begin{array}{c}-1.108^{* * *} \\
(0.157)\end{array}$ & $\begin{array}{c}-1.211^{* * *} \\
(0.118)\end{array}$ & $\begin{array}{c}-1.221 * * * \\
(0.119)\end{array}$ \\
\hline Skilled workers & $\begin{array}{c}-0.521 * * * \\
(0.0990)\end{array}$ & $\begin{array}{c}-0.533 * * * \\
(0.113)\end{array}$ & $\begin{array}{c}-0.508^{* * *} \\
(0.112)\end{array}$ & $\begin{array}{c}-0.519 * * * \\
(0.130)\end{array}$ & $\begin{array}{c}-0.544^{* * * *} \\
(0.104)\end{array}$ & $\begin{array}{c}-0.567 * * * \\
(0.104)\end{array}$ \\
\hline Farmers & ref & ref & ref & ref & ref & ref \\
\hline Lower skilled workers & $\begin{array}{c}0.0661 \\
(0.0908)\end{array}$ & $\begin{array}{l}0.0402 \\
(0.105)\end{array}$ & $\begin{array}{l}0.0185 \\
(0.105)\end{array}$ & $\begin{array}{l}0.0124 \\
(0.124)\end{array}$ & $\begin{array}{l}0.00503 \\
(0.0951)\end{array}$ & $\begin{array}{c}-0.00536 \\
(0.0947)\end{array}$ \\
\hline Unskilled workers & $\begin{array}{c}0.705^{* * *} \\
(0.125)\end{array}$ & $\begin{array}{c}0.768^{* * *} \\
(0.156)\end{array}$ & $\begin{array}{c}0.682 * * * \\
(0.140)\end{array}$ & $\begin{array}{c}0.814 * * * \\
(0.183)\end{array}$ & $\begin{array}{c}0.613^{* * *} \\
(0.129)\end{array}$ & $\begin{array}{c}0.609^{* * *} \\
(0.129)\end{array}$ \\
\hline \multicolumn{7}{|l|}{ G1 (Paternal/Maternal) } \\
\hline Higher occupations & & & & & $\begin{array}{c}-0.347 * * * \\
(0.122)\end{array}$ & $\begin{array}{c}-0.332 * * \\
(0.146)\end{array}$ \\
\hline Skilled workers & & & & & $\begin{array}{l}0.0524 \\
(0.105)\end{array}$ & $\begin{array}{c}-0.0397 \\
(0.129)\end{array}$ \\
\hline Farmers & & & & & ref & ref \\
\hline Lower skilled workers & & & & & $\begin{array}{l}0.187^{* *} \\
(0.0941)\end{array}$ & $\begin{array}{c}0.269^{* *} \\
(0.121)\end{array}$ \\
\hline Unskilled workers & & & & & $\begin{array}{l}0.281^{* *} \\
(0.118)\end{array}$ & $\begin{array}{c}0.142 \\
(0.126)\end{array}$ \\
\hline \multicolumn{7}{|l|}{ PG1 (Paternal) } \\
\hline Higher occupations & & $\begin{array}{c}-0.538^{* * *} \\
(0.170)\end{array}$ & & $\begin{array}{c}-0.577 * * * \\
(0.198)\end{array}$ & & \\
\hline Skilled workers & & $\begin{array}{l}-0.0925 \\
(0.129)\end{array}$ & & $\begin{array}{l}-0.0411 \\
(0.150)\end{array}$ & & \\
\hline Farmers & & ref & & ref & & \\
\hline Lower skilled workers & & $\begin{array}{c}0.141 \\
(0.0973)\end{array}$ & & $\begin{array}{l}0.0991 \\
(0.113)\end{array}$ & & \\
\hline Unskilled workers & & $\begin{array}{l}-0.0103 \\
(0.116)\end{array}$ & & $\begin{array}{l}-0.132 \\
(0.133)\end{array}$ & & \\
\hline \multicolumn{7}{|l|}{ MG1 (Maternal) } \\
\hline Higher occupations & & & $\begin{array}{l}-0.132 \\
(0.156)\end{array}$ & $\begin{array}{c}-0.0554 \\
(0.186)\end{array}$ & & \\
\hline Skilled workers & & & $\begin{array}{c}0.137 \\
(0.137)\end{array}$ & $\begin{array}{l}0.0781 \\
(0.163)\end{array}$ & & \\
\hline Farmers & & & ref & ref & & \\
\hline Lower skilled workers & & & $\begin{array}{c}0.131 \\
(0.0988)\end{array}$ & $\begin{array}{c}0.126 \\
(0.114)\end{array}$ & & \\
\hline
\end{tabular}




\section{Class, Status, Earnings-Three Generations in Sweden 987}

TABLE 3 (CONTINUED)

ORDERED LOGIT ESTIMATES (LOG ODDS RATIOS) OF G3 CLASS ATTAINMENT (HISCLASS)

\begin{tabular}{|c|c|c|c|c|c|c|}
\hline & Model 1 & Model 2 & Model 3 & Model 4 & Model 5 & Model 6 \\
\hline Unskilled workers & & & $\begin{array}{c}0.279 * * * \\
(0.105)\end{array}$ & $\begin{array}{l}0.239 * \\
(0.123)\end{array}$ & & \\
\hline
\end{tabular}

Period (rc: 1945-1990)

$\begin{array}{ccccccc}1813-1899 & 0.828 * * * & 0.846 * * * & 0.881 * * * & 0.892 * * * & 0.869 * * * & 0.861 * * * \\ & (0.111) & (0.133) & (0.126) & (0.158) & (0.113) & (0.140) \\ 1900-1944 & 0.525 * * * & 0.476 * * * & 0.561 * * * & 0.499 * * * & 0.551 * * * & 0.482 * * * \\ & (0.0810) & (0.0895) & (0.0888) & (0.0994) & (0.0831) & (0.112)\end{array}$

Interactions: Period 1813-1899 x G1 HISCLASS

$\begin{array}{lr}\text { Higher occupations } & 0.0348\end{array}$

Skilled workers

Lower skilled workers

Unskilled workers

Interactions: Period 1900-1944 x G1 HISCLASS

Higher occupations

Skilled workers

Lower skilled workers

Unskilled workers

\begin{tabular}{lllllll}
\hline Observations & 4,261 & 3,366 & 3,428 & 2,533 & 4,261 & 4,261 \\
Pseudo $R^{2}$ & 0.069 & 0.076 & 0.068 & 0.075 & 0.072 & 0.073 \\
\hline
\end{tabular}

Notes: Models control for age, age squared, residing in metropolitan area and lifetime migration. Models include analytical weights based on the number of underlying observations in the data for each G3 individual. $* \mathrm{p}<0.1, * * \mathrm{p}<0.05, * * * \mathrm{p}<0.01$

P-value for Wald-test of $\beta_{\mathrm{PG} 1 \text {, higher occupations }}=\beta_{\mathrm{MG} 1 \text {, higher occupations }}$ (Model 4): 0.061

P-value for Wald-test of $\beta_{\mathrm{PG} 1 \text {, unskilled workers }}=\beta_{\mathrm{MG} 1 \text {, unskilled workers }}$ (Model 4): 0.051

Source: See Table 1.

and whether residing in a metropolitan area. For each respective ancestral influence, the log odds ratios are calibrated against the reference category (farmers). Because lower numbers in HISCLASS mean higher class attainment, positive coefficients (log odds ratios) imply lower class attainment, and negative coefficients higher class attainment, compared 
to the reference category (farmers). For example, if having a father in the highest class is associated with a negative log odds ratio, this implies a lower likelihood of a son ending up in a lower class compared to having a father in the farmer class. Furthermore, the size of the log odds ratio indicates the strength of this association, allowing for comparisons between all classes in each respective ancestral generation.

Column 1 in Table 3 serves as a reference. The analysis disregards the influence from the grandparental generation. Unsurprisingly, the father's influence on son's attainment is strong, implying substantial class persistence across two generations. Having a father in the higher occupations or skilled worker group implies a significantly lower likelihood of ending up in a lower class compared to if the father is a farmer, as shown by the negative coefficients. The more strongly negative log odds ratio observed for sons with fathers in higher occupations $(-1.3)$, however, indicates a higher likelihood for high status attainment compared to sons whose fathers were skilled workers $(-0.5)$. There are also indications of strong intergenerational class persistence at the lower end of the status hierarchy, as indicated by the positive coefficients. In fact, the pattern indicates a rather linear gradient in terms of the intergenerational transmission of class. More specifically, the lower the attained class of the father, the higher the probability that the son remains in a lower class.

In column 2, we add paternal grandfather's (PG1) class attainment which does little to change the father-son (G2-G3) association. More interestingly, there is an association between paternal grandfather and grandson (PG1-G3), even if weaker than that between father and son. While coefficients are not statistically significant for each class, having a paternal grandfather in a higher class than the farmer class is associated with a lower chance of low class attainment. Furthermore, having a lower skilled or unskilled paternal grandfather is associated with a higher chance of low class attainment. In column 3, we look at associations with the maternal grandfather's class. The pattern is similar to the one observed for the influence of the paternal grandfather's class, but we find a stronger and statistically significant impact of having a maternal grandfather with an unskilled occupation. Again, we find a grandparent influence controlling for parental generation across some social groups.

Both paternal (PG1) and maternal grandfather's (MG1) class are included in column 4, which does not change the basic association between father and son, nor affect the association between grandfather and grandson. The substantive conclusion remains: having a maternal grandfather with an unskilled occupation significantly increases the likelihood of low class attainment for the third generation. Grandsons whose 
paternal grandfathers belong to the higher occupations enjoy a significantly higher probability of attaining this class. ${ }^{12}$ In column 5 we use the highest observed grandparental class, regardless of whether on the maternal or paternal side, which also maximizes the sample size. This does not change the results but further supports the conclusion of an independent influence of the grandfather on class attainment, in addition to any influence going through the father, at either end of the status hierarchy. Having a grandfather in the highest class is associated with higher class attainment, while a grandfather in the working class is associated with lower class attainment, when controlling for the attainment of the father.

Column 6 shows the changes over time in the influence of grandparents. Here we include a three-period interaction, with the post-WWII period as the reference category. Hence, the log odds ratios for the baseline refer to the post-WWII period and the interaction log odds ratios indicate the extent to which the associations are different in earlier periods. Overall, the results suggest few significant changes over time in the grandparental influence. The exception is the first half of the twentieth century, a time characterized by overwhelming labor market changes occurring in parallel with a rapid industrialization (Erikson 1983; Schön 2000). During this period, the disadvantage experienced by grandsons whose grandfathers belonged to the unskilled working class was accentuated, as indicated by the significant and positive interaction effect. A significant disadvantage is also observed among individuals with skilled worker grandfathers. Overall, however, the grandparental influence on class attainment does not appear to change that much over the nineteenth and the twentieth centuries.

\section{Occupational Attainment (HISCAM)}

The preceding analysis suggested the presence of a significant grandparental influence on class attainment controlling for the influence of the parental generation. We now examine the impact of grandfather occupational status, measured by the continuous scale HISCAM. ${ }^{13}$ The baseline model is given in column 1 in Table 4 . It shows that almost 40 percent

\footnotetext{
12 The difference between having an unskilled paternal and maternal grandfather is on the border of being statistically significant (Wald test, $\mathrm{p}=0.051$ ), and the result is similar for higher occupations $(\mathrm{p}=0.061)$.

${ }_{13}$ The age-specific HISCAM scores were transformed into a measurement of permanent occupational status. Thus the coefficients of intergenerational transmission-obtained by ordinary lease square (OLS) regression — can be interpreted as intergenerational status elasticities. Similar to the previous analysis, models presented in all subsequent sections are estimated using analytical weights (results without weights are highly similar).
} 
TABLE 4

OLS ESTIMATES OF OCCUPATIONAL STATUS ASSOCIATIONS (G3 HISCAM AS DEPENDENT VARIABLE)

\begin{tabular}{lcccccc}
\hline \hline & Model 1 & Model 2 & Model 3 & Model 4 & Model 5 & Model 6 \\
\hline G2 & $0.377^{* * *}$ & $0.340^{* * *}$ & $0.352^{* * *}$ & $0.324^{* * *}$ & $0.344^{* * *}$ & $0.346^{* * *}$ \\
& $(0.0274)$ & $(0.0304)$ & $(0.0301)$ & $(0.0345)$ & $(0.0273)$ & $(0.0270)$ \\
G1 (Paternal/Maternal) & & & & & & \\
& & & & & $0.108^{* * *}$ & $0.0875^{* *}$ \\
& & & & & $(0.0293)$ & $(0.0342)$ \\
PG1 (Paternal) & & $0.131^{* * *}$ & & $0.117^{* * *}$ & & \\
& & $(0.0385)$ & & $(0.0447)$ & & \\
MG1 (Maternal) & & & & & & \\
& & & $0.0914 * * *$ & $0.0620^{*}$ & & \\
Period (rc: 1945-1990) & & & $(0.0324)$ & $(0.0347)$ & & \\
1813-1899 & & & & & & \\
& $0.0236^{* * *}$ & $0.0198^{* * *}$ & $0.0225^{* * *}$ & $0.0190^{* * *}$ & $0.0222 * * *$ & $0.0210^{* * *}$ \\
1900-1944 & $(0.00597)$ & $(0.00637)$ & $(0.00663)$ & $(0.00724)$ & $(0.00582)$ & $(0.00551)$ \\
& $0.00868^{*}$ & $0.00986^{*}$ & 0.00555 & 0.00777 & 0.00765 & 0.00725 \\
& $(0.00515)$ & $(0.00555)$ & $(0.00543)$ & $(0.00594)$ & $(0.00513)$ & $(0.00504)$
\end{tabular}

Interactions: Period x G1 SES

1813-1899

1900-1944

\begin{tabular}{lllllll}
\hline Observations & 4,282 & 3,539 & 3,615 & 2,872 & 4,282 & 4,282 \\
$R^{2}$ & 0.184 & 0.195 & 0.190 & 0.202 & 0.190 & 0.191 \\
\hline
\end{tabular}

Notes: Models control for residing in metropolitan area and lifetime migration. Models include analytical weights based on the number of underlying observations in the data for each G3 individual.

$* \mathrm{p}<0.1, * * \mathrm{p}<0.05, * * * \mathrm{p}<0.01$

P-value for Wald-test of $\beta_{\mathrm{PG} 1}=\beta_{\mathrm{MG} 1}$ (Model 4): 0.001

Source: See Table 1.

of the parental generation's (G2) advantage or disadvantage is transmitted to the subsequent generation of grandsons (G3), as indicated by the statistically significant elasticity of 0.38 . This is a sizeable father-son association in occupational status, exceeding those typically observed in previous research focusing on earnings (see next section).

Adding paternal grandfather occupational status (column 2) only slightly reduces the father-son association. The association between paternal grandfather and grandson attainment is substantially weaker0.13 for grandfather-grandson, compared to 0.34 for father-son-but still statistically significant. Consequently, even controlling for parental 
influence, the paternal grandfather's occupational attainment significantly influences the grandson's attainment. Looking at the influence of the maternal grandfather (MG1), in column 3, the association is somewhat weaker than that observed for the paternal grandfather (PG1), yet still statistically significant (0.09 for MG1 compared to 0.13 for PG1).

Including the occupational status of both the paternal (PG1) and maternal grandfather (MG1) in column 4 does not change grandparental influence; both the maternal and paternal grandfathers matter for occupational attainment, but the influence of the paternal grandfather is larger (0.12 compared to 0.06$).{ }^{14}$ Given the results so far, it is hardly surprising that the association between the combined grandfather-grandson occupational scores is similar to the paternal grandfather-grandson association (column 5) with a combined elasticity of 0.11 (statistically significant). The time period interactions in column 6 , are not statistically significant. Hence, similar to class attainment, the grandparental influence on occupational status does not change markedly over the nineteenth and the twentieth centuries, despite major changes taking place in occupational structure and dominant mechanisms of recruitment.

\section{Earnings}

We now turn to the earnings association shown in Table 5. In the baseline model (column 1) we have the earnings association between fathers and sons. The elasticity is 0.18 and statistically significant, which is in line with similar two-generation estimates in other studies for Sweden, typically ranging between 0.2 and 0.3 (Björklund and Jäntti 1997; Björklund, Lindahl, and Plug 2006; Lindahl et al. 2015). This suggests that 18 percent of an earnings advantage, or disadvantage, in one generation is transmitted to the next generation. Thus, the simple intergenerational (G2-G3) transmission of occupational status appears to be a considerably stronger process compared to earnings, as suggested by the elasticity of 0.38 relative to 0.18 .

Adding paternal grandfather's (PG1) lifetime earnings to the model (column 2) shows no significant grandparent effect, but attenuates the parental influence, which nevertheless remains statistically and economically significant. Similarly, there is no statistically significant association between the lifetime earnings of the maternal grandfather (MG1) and those of the grandson (G3), controlling for the attainment of the father

\footnotetext{
${ }^{14}$ The coefficients are significantly different from each other (Wald test, $p$-value $=0.001$ ).
} 
TABLE 5

OLS ESTIMATES OF EARNINGS ASSOCIATIONS

(G3 EARNINGS AS DEPENDENT VARIABLE)

\begin{tabular}{lccccc}
\hline \hline & Model 1 & Model 2 & Model 3 & Model 4 & Model 5 \\
\hline G2 & $0.183^{* * *}$ & $0.150^{* * *}$ & $0.208^{* * *}$ & $0.193^{* *}$ & $0.176^{* * *}$ \\
& $(0.0311)$ & $(0.0421)$ & $(0.0414)$ & $(0.0813)$ & $(0.0317)$
\end{tabular}

G1 (Paternal/Maternal)

PG1 (Paternal)

MG1 (Maternal)

\begin{tabular}{lccccc}
\hline Observations & 2,241 & 1,295 & 1,458 & 512 & 2,241 \\
$R^{2}$ & 0.037 & 0.044 & 0.038 & 0.054 & 0.038 \\
\hline
\end{tabular}

Notes: Models control for residing in metropolitan area and life time migration. Models include analytical weights based on the number of underlying observations in the data for each G3 individual.

$* \mathrm{p}<0.1, * * \mathrm{p}<0.05, * * * \mathrm{p}<0.01$

P-value for Wald-test of $\beta_{\mathrm{PG} 1}=\beta_{\mathrm{MGl}}$ (Model 4): 0.3112

Source: See Table 1.

(G2) (column 3). The magnitudes of the coefficients for maternal and paternal grandfathers are similar.

When including the lifetime earnings of both the maternal (MG1) and paternal (PG1) grandfather in the same model (column 4), both coefficients are of a similar magnitude (0.05 and 0.06, respectively), but statistically insignificant. When maximizing the sample size by using the highest observed lifetime earnings in the grandparental generation, regardless of whether this is observed on the maternal or the paternal side, the results remain similar. Column 5 shows only a very modest, and statistically insignificant, association in lifetime earnings between grandfathers and grandsons, when controlling for the father's earnings. While the elasticity for fathers' earnings is close to 0.2 , it is only 0.03 for grandfathers. Thus, in terms of earnings we find very little to indicate an independent impact of grandparental earnings on grandchildren's earnings when controlling for the impact of parental earnings. This result is quite similar to the one for the Malmö cohort, reported in Lindahl et al. (2015, Table 9), where the corresponding coefficient for grandfather was 0.08 , and for father 0.28 , with the grandfather coefficient only being statistically significant at the 10-percent level. 


\section{SENSITIVITY ANALYSIS}

To ascertain whether the different results for earnings and occupational attainment are due to the different samples used in the two analyses, we estimated a model for both outcomes using the same sample (family lines for which we have information on both earnings and occupational status). The results are displayed in Table 6 and they are similar to the ones based on the larger samples. We continue to find a clear association between the rankings of the grandfather and the grandson for occupational attainment (HISCAM) even when controlling for the attainment of the father, but only an association between father and son for earnings. This confirms that the results for the occupational outcomes and earnings outcomes are indeed very different.

A common concern in historical mobility studies is that farmers drive the results by being a large and rather special group given ownership of land and its role for intergenerational inheritance (Long and Ferrie 2013; Hout and Guest 2013; Xie and Killewald 2013). To assess the role of farmers, we estimated the same models excluding farmers in all three generations. The results are similar to those based on the full sample, both in terms of occupational status and earnings (detailed results available from the authors). We are thus confident that the patterns presented are not driven by the outcomes of farmers.

There are several possible explanations for a positive association between the outcomes of grandfathers and grandsons. One explanation for direct influence from grandfathers to grandsons would be overlapping life spans. We assume that while socio-emotional pathways require a certain level of proximity and interaction between grandparents and their children (see Zeng and Xie 2014; Knigge 2015), this is not necessary for the economic pathways, because resource transfers across generations do not depend on social interaction. To examine this in more detail, we estimate models including indicators of life status of the grandfather (G1) at the time of their grandson's (G3) birth. Table 7 displays the results for the lifetime measures of HISCAM and earnings, respectively. Naturally there is a considerable proportion for which the grandparental life status is unknown (65 percent in in the HISCAM sample and 14 percent in the earnings sample). Grandfather being alive is the reference category. The base coefficient for grandfather is statistically significant and of a considerable magnitude for occupational status, but small and insignificant for earnings. Even though the interaction effect for grandfather being dead is not statistically significant, it is negative and of a considerable magnitude $(-0.150)$, and it is also similar for unknown life status (a model 
TABLE 6

OLS ESTIMATES OF G3 HISCAM AND EARNINGS ASSOCIATIONS, BASED ON IDENTICAL ANALYTICAL SAMPLES

\begin{tabular}{lcc}
\hline \hline & HISCAM & Earnings \\
\hline G2 & $0.331^{* * *}$ & $0.144^{* * *}$ \\
& $(0.0528)$ & $(0.0463)$ \\
G1 (Paternal/Maternal) & $0.132^{* *}$ & 0.0367 \\
& $(0.0608)$ & $(0.0373)$ \\
\hline Observations & 746 & 746 \\
$R^{2}$ & 0.230 & 0.060 \\
\hline
\end{tabular}

Note: Models control for residing in metropolitan area and lifetime migration. Models include analytical weights based on the number of underlying observations in the data for each G3 individual.

$* \mathrm{p}<0.1,{ }^{*} \mathrm{p}<0.05, * * * \mathrm{p}<0.01$

Source: See Table 1.

TABLE 7

IMPACT OF GRANDPARENTAL LIFE STATUS AND RESIDENCE ON INTERGENERATIONAL ASSOCIATIONS (OLS)

\begin{tabular}{lcc}
\hline \hline & HISCAM & Earnings \\
\hline G2 & $0.343^{* * *}$ & $0.177^{* * *}$ \\
& $(0.0270)$ & $(0.0317)$ \\
G1 (Paternal/Maternal) & $0.219^{* * *}$ & -0.0128 \\
& $(0.0714)$ & $(0.0505)$
\end{tabular}

G1 life status

Unknown

$\begin{array}{cc}0.0107 * * & 0.00953 \\ (0.00503) & (0.0304) \\ 0.00580 & 0.0128 \\ (0.00700) & (0.0335)\end{array}$

Alive

ref

ref

Interactions G1 life status*SES

\begin{tabular}{lcc} 
Unknown & -0.121 & 0.0301 \\
& $(0.0774)$ & $(0.0842)$ \\
Dead & -0.150 & -0.0473 \\
& $(0.117)$ & $(0.0557)$ \\
\hline Observations & 4,282 & 2,241 \\
$R^{2}$ & 0.192 & 0.039 \\
\hline
\end{tabular}

Note: Models control for residing in metropolitan area and life time migration. Models include analytical weights based on the number of underlying observations in the data for each G3 individual.

$* \mathrm{p}<0.1, * * \mathrm{p}<0.05, * * * \mathrm{p}<0.01$

Source: See Table 1. 
with grandfather dead/unknown merged into a single category yields an estimate of -0.128 , $p$-value $=0.10$ ). The base coefficient, which refers to grandfather being alive, is also much larger than in the model without interactions ( 0.219 versus 0.108$)$. This clearly points to the grandfathergrandson association being stronger when life spans overlap, but as the coefficient is not statistically significant it is difficult to draw a definitive conclusion.

\section{CONCLUSIONS}

In this article we study associations in socioeconomic attainment across three generations in Sweden over almost 200 years. We look at three dimensions of social status-social class, occupational status, and earnings - and distinguish between the impact of maternal and paternal grandfathers. Our results show clear associations between grandfathers' class and occupational status and grandsons' outcomes, when controlling for the associations between fathers and sons. Overall, the association is stronger for the paternal grandfather than for the maternal grandfather, even though they are both important. These associations are stable over time which is remarkable given the dramatic changes in labor markets and occupational structure taking place in the period we are looking at.

For earnings we find no significant association at all between grandfathers and grandsons, regardless of whether we focus on the paternal side, the maternal side, or both sides combined. Hence, while there appears to be clear persistence in class and occupational status across multiple generations, there is little persistence in earnings beyond two generations. Lindahl et al. (2015) also found much stronger intergenerational persistence over three generations for education than for earnings in their analysis of the Malmö cohort. Similar differences in two-generation associations between class and earnings have been shown for Britain, leading Robert Erikson and John Goldthorpe (2010) to conclude that class likely is a more stable indicator of socioeconomic status than income, at least in cases when good measures of life-time income is lacking, which is not a major issue for our study. A lack of close correlation between income and class dimensions of intergenerational mobility has also recently been pointed out by Jo Blanden (2013), who interprets this as indicating that class and income are two equally important aspects of socioeconomic status. Richard Breen, Carina Mood, and Jan O. Jonsson (2016) reach a similar conclusion after a systematic comparison of intergenerational mobility in earnings and social class in contemporary Sweden, using high-quality register data. 
Our analysis has some important limitations. First, as it is based on local population registers for the early part of the period analyzed, we cannot completely rule out the existence of selection bias due to migration. Even though in-migrants and out-migrants are fairly similar in observed characteristics, there could still be differences between them in unobserved factors related to social mobility. Another limitation is the limited geographical coverage, which makes it difficult to interpret the results as representative for Sweden as a whole. Having said this, however, the area studied is in most ways typical and similar to other rural and semi-urban places in Sweden in this period, and we have no reason to believe that the patterns shown here would not be similar in other similar contexts. Despite these limitations the results give a valuable contribution to our knowledge about multigenerational social mobility, which is impossible to study at this level of detail in most nationally representative data sources.

Obviously, the mere existence of a grandfather-grandson association cannot be taken as evidence for a direct impact from grandfathers on grandsons, as it could be related to unobserved factors determining the different socioeconomic outcomes that we measure. These unobserved factors may be persistently transmitted through the generations, but may not translate fully into social outcomes in every generation, producing a lower persistence in observed outcomes. This could work through reputation, networks, or transmission of attitudes or abilities, all producing an indirect effect from the grandfather to the grandson. We find some indications that the association between the occupational outcomes of grandfathers and grandsons is stronger when their life spans overlap. Nonetheless, it is difficult to rule out the possibility that a socio-emotional influence or a transmission of cultural capital (cf. Zeng and Xie 2014) could be an important explanation for the association between the occupational status of grandfathers and grandsons. The fact that the associations are stronger, if anything, for the paternal grandfathers than for the maternal even when controlling for the status of the father, does not indicate that the biological or genetic pathway is very important.

Taken together, our analysis contributes to a growing literature on multigenerational transmission of socioeconomic outcomes in a variety of contexts that is beginning to question many of the old truths about social mobility. A major challenge to this literature is how to interpret these new findings in terms of determinants of socioeconomic outcomes and inequality, and how they have changed through history. More detailed empirical work on the mechanisms of the transmission, beyond 


\section{Class, Status, Earnings-Three Generations in Sweden}

simple intergenerational correlations, is needed to advance our knowledge further, and in this quest more long-term historical evidence is of utmost importance.

\section{REFERENCES}

Abramaitzky, Ran, Leah Platt Boustan, and Katherine Eriksson. "Europe's Tired, Poor, Huddled Masses: Self-Selection and Economic Outcomes in the Age of Mass Migration." American Economic Review 102, no. 5 (2012): 1832-56.

Baum, Christopher F. An Introduction to Modern Econometrics Using Stata. College Station, TX: Stata Press, 2006.

Becker, Gary, and Nigel Tomes. "Human Capital and the Rise and Fall of Families." Journal of Labor Economics 4, Suppl. (1986): 1-39.

Beenstock, Michael. Heredity, Family, and Inequality. A Critique of Social Sciences. Cambridge, MA: MIT Press, 2012.

Bengtson, Vern L. "Beyond the Nuclear Family: The Increasing Importance of Multigenerational Bonds." Journal of Marriage and Family 63, no. 1 (2001): 1-16.

Bengtsson, Tommy, Martin Dribe, Luciana Quaranta, et al. The Scanian Economic Demographic Database. Version 4.0 (Machine-readable database). Lund: Lund University, Centre for Economic Demography, 2014.

Björklund, Anders, and Markus Jäntti. "Intergenerational Income Mobility in Sweden Compared to the United States." American Economic Review 87, no. 5 (1997): $1009-18$.

—. "Intergenerational Mobility of Socio-Economic Status in Comparative Perspective." Nordic Journal of Political Economy 26, no. 1 (2000): 3-32.

_ . "Intergenerational Income Mobility and the Role of Family Background." In The Oxford Handbook of Economic Inequality edited by Wiemer Salverda, Brian Nolan and Timothy M. Smeeding, 465-74. Oxford: Oxford University Press, 2009. - "How Important is Family Background for Labor-Economic Outcomes?" Labour Economics 19, no. 4 (2012): 465-74.

Björklund, Anders, Markus Jäntti, and Gary Solon. "Nature and Nurture in the Intergenerational Transmission of Socioeconomic Status: Evidence from Swedish Children and Their Biological and Rearing Parents." B.E. Journal of Economic Analysis \& Policy 7, no. 1 (2007): 1-21.

Björklund, Anders, Mikael Lindahl, and Erik Plug. "The Origins of Intergenerational Associations: Lessons from Swedish Adoption Data." Quarterly Journal of Economics 115, no. 3 (2006): 955-88.

Black, Sandra, and Paul. J. Devereux. "Recent Developments in Intergenerational Mobility." In Handbook of Labor Economics, Volume 4b, edited by David Card and Orley Ashenfelter, 1487-541. Amsterdam: Elsevier, 2011.

Blanden, Jo. "Cross-Country Rankings in Intergenerational Mobility: A Comparison of Approaches from Economics and Sociology." Journal of Economic Surveys 27, no. 1 (2013): 38-73.

Blau, Peter M., and Otis D. Duncan. The American Occupational Structure. New York: Wiley, 1967. 
Braun, Sebastian T., and Jan Stuhler. "The Transmission of Inequality Across Multiple Generations: Testing Recent Theories with Evidence from Germany.” Unpublished Manuscript, 2015.

Breen, Richard, Carina Mood, and Jan O. Jonsson. "How Much Scope for a Mobility Paradox? The Relationship between Social and Income Mobility in Sweden." Sociological Science 3 (2016): 39-60.

Chan, Tak Wing, and Vikki Boliver. "The Grandparents Effect in Social Mobility: Evidence from British Birth Cohort Studies." American Sociological Review 78, no. 4 (2013): 662-78.

Clark, Gregory. The Son Also Rises: Surnames and the History of Social Mobility. Princeton: Princeton University Press, 2014.

Clark, Gregory, and Neil Cummins. "Intergenerational Wealth Mobility in England, 1858-2012: Surnames and Social Mobility.” Economic Journal 125, no. 582 (2015): 61-85.

Corak, Miles. "Income Inequality, Equality of Opportunity, and Intergenerational Mobility." Journal of Economic Perspectives 27, no. 3 (2013): 79-102.

Dribe, Martin. "Migration of Rural Families in Nineteenth Century Southern Sweden. A Longitudinal Analysis of Local Migration Patterns." History of the Family 8, no. 2 (2003a): 247-65.

_ . "Dealing with Economic Stress Through Migration: Lessons from Nineteenth Century Rural Sweden.” European Review of Economic History 7, no. 3 (2003b): 271-99.

Dribe, Martin, Jonas Helgertz, and Bart van de Putte. "Did Social Mobility Increase During the Industrialization Process? A Micro-Level Study of a Transforming Community in Southern Sweden 1828-1968." Research in Social Stratification and Mobility 41, no. 1 (2015): 25-39.

Erikson, Robert. Changes in Social Mobility in Industrial Nations: The Case of Sweden. Stockholm: Swedish Institute for Social Research, 1983.

Erikson, Robert, and John H. Goldthorpe. "Has Social Mobility in Britain Decreased? Reconciling Divergent Findings on Income and Class Mobility." British Journal of Sociology 61, no. 2 (2010): 211-30.

Erola, Jani, and Pasi Moisio. "Social Mobility over Three Generations in Finland, 1950-2000.” European Sociological Review 23, no. 2 (2007): 169-83.

Hällsten, Martin. "Inequality Across Three and Four Generations in Egalitarian Sweden: $1^{\text {st }}$ and $2^{\text {nd }}$ Cousin Correlations in Socio-Economic Outcomes." Research in Social Stratification and Mobility 35, no. 1 (2014): 10-33.

Hendrickx, Julien. "ISCO: Stata Module to Recode 4 digit ISCO-68 Occupational Codes, Statistical Software Components S425801.” Boston College, Department of Economics, 2002.

Hertel, Florian R., and Olaf Groh-Samberg. "Class Mobility Across Three Generations in the U.S. and Germany." Research in Social Stratification and Mobility 35, no. 1 (2014): 35-52.

Hodge, Robert W. “Occupational Mobility as a Probability Process.” Demography 3, no. 1 (1966): 19-34.

Hout, Michael, and Avery M. Guest. "Intergenerational Occupational Mobility in Great Britain and the United States since 1850: Comment." American Economic Review 103, no. 5 (2013): 2021-40. 


\section{Class, Status, Earnings-Three Generations in Sweden}

Jaeger, Mads M. “The Extended Family and Children's Educational Success.” American Sociological Review 77, no. 6 (2012): 903-22.

Jäntti, Markus, and Stephen P. Jenkins. "Income Mobility." IZA Discussion Paper No. 7730. Bonn: IZA, 2013.

Knigge, Antonie. Sources of Sibling Similarity. Status Attainment in the Netherlands during Modernization. Ph.D. Thesis, Utrecht University, 2015.

Lambert, Paul S., Richard L. Zijdeman, Marco H. D. Van Leeuwen, et al. "The Construction of HISCAM: A Stratification Scale Based on Social Interactions for Historical Comparative Research." Historical Methods 46, no. 2 (2013): 77-89.

Lindahl, Mikael, Mårten Palme, Sofia Sandgren Massih, et al. "Long-Term Intergenerational Persistence of Human Capital: An Empirical Analysis of Four Generations." Journal of Human Resources 50, no. 1 (2015): 1-33.

Long, Jason, and Joseph Ferrie. "Grandfathers Matter(ed). Occupational Mobility Across Three Generations in the U.S. and Britain, 1850-1910." Unpublished Manuscript, 2012.

_. "Intergenerational Occupational Mobility in Great Britain and the United States since 1850." American Economic Review 103, no. 4 (2013): 1109-37.

Mare, Robert D. "A Multigenerational View of Inequality." Demography 48, no. 1 (2011): 1-23.

Modin, Bitte, and Johan Fritzell. "The Long Arm of the Family: Are Parental and Grandparental Earnings Related to Young Men's Body Mass Index and Cognitive Ability?" International Journal of Epidemiology 38, no. 3 (2009): 733-44.

Modin, Bitte, Robert Erikson, and Denny Vågerö. "Intergenerational Continuity in School Performance: Do Grandparents Matter?” European Sociological Review 29, no. 4 (2013): 858-70.

Olsson, Mats, and Patrick Svensson. "Agricultural Growth and Institutions: Sweden, 1700-1860." European Review of Economic History 14, no. 2 (2010): 275304.

Pfeffer, Fabian, and Martin Hällsten. "Mobility Regimes and Parental Wealth: The United States, Germany and Sweden in Comparison." PSC Research Report 12-766. Population Studies Center, University of Michigan, 2012.

Piketty, Thomas. Capital in the Twenty-First Century. Belknap Press, 2014.

Prandy, Ken. "The Social Interaction Approach to the Measurement and Analysis of Social Stratification." International Journal of Sociology and Social Policy 19, no. 9/10/11 (1999): 215-49.

Schön, Lennart. Från hantverk till fabriksindustri. Svensk textiltillverkning 1820-1870. Kristianstad: Arkiv, 1979.

_. En modern svensk ekonomisk historia: tillväxt och omvandling under två sekel. Stockholm: SNS, 2000.

Solon, Gary. "Intergenerational Income Mobility in the United States." American Economic Review 82, no. 3 (1992): 393-408.

- "Cross-country Differences in Intergenerational Earnings Mobility." Journal of Economic Perspectives 16, no. 3 (2002): 59-66.

_. "Theoretical Models of Inequality Transmission Across Multiple Generations." Research in Social Stratification and Mobility 35, no. 1 (2014): 13-18.

Solon, Gary, Steven J. Haider, and Jeffrey Wooldridge. "What Are We Weighting for?" NBER Working Paper No. 18859, Cambridge, MA, 2013. 
Stanfors, Maria. Mellan arbete och familj. Ett dilemma för kvinnor i 1900-talets Sverige. Stockholm: SNS, 2007.

Stuhler, Jan. "Mobility Across Multiple Generations: The Iterated Regression Fallacy." IZA Discussion Paper 7072, Bonn, Germany, 2012.

Svensson, Patrick. "Peasants and Entrepreneurship in the Nineteenth-Century Agricultural Transformation of Sweden.” Social Science History 30, no. 3 (2006): $387-429$.

Treiman, Donald J. “Industrialization and Social Stratification.” In Social Stratification: Research and Theory for the 1970s, edited by E. O. Laumann, 207-234. Indianapolis and New York: The Bobbs-Merrill Company, Inc., 1970.

Van Leeuwen, Marco H. D., and Ineke Maas. HISCLASS. A Historical International Social Class Scheme. Leuven: Leuven University Press, 2011.

Van Leeuwen, Marco H. D., Ineke Maas, and Andrew Miles. HISCO. Historical International Standard Classification of Occupations. Leuven: Leuven University Press, 2002.

Warren, John R., and Robert M. Hauser. "Social Stratification Across Three Generations: New Evidence from the Wisconsin Longitudinal Study." American Sociological Review 62, no. 4 (1997): 561-72.

$\mathrm{Xie}, \mathrm{Yu}$, and Alexandra Killewald. "Intergenerational Occupational Mobility in Great Britain and the United States Since 1850: Comment." American Economic Review 103, no. 5 (2013): 2003-2020.

Zeng, Zhen, and Yu Xie. "The Effects of Grandparents on Children's Schooling: Evidence from Rural China.” Demography 51, no. 2 (2014): 599-617.

Zimmerman, David J. "Regression Toward Mediocrity in Economic Stature." American Economic Review 82, no. 3 (1992):409-29. 